\title{
Correction to: Ageratum houstonianum and Rudbeckia hirta, new hosts for the powdery mildews Golovinomyces asterum and Golovinomyces ambrosiae
}

\author{
K. Sharifi ${ }^{1}$ - M. Darvishnia ${ }^{1}$ - S. A. Khodaparast ${ }^{2} \cdot$ A. Bazgir $^{1}$ \\ Published online: 7 October 2020 \\ (C) Australasian Plant Pathology Society Inc. 2020
}

\section{Correction to: Australasian Plant Disease Notes https://doi.org/10.1007/s13314-020-00399-4}

The original version of this article unfortunately contained mistakes introduced during the production process. There were mistakes in numbering of the figures. The corrections are given in the following list:

(1) In the seventh paragraph, last sentence, the citations for Figs. 2 and 3 should be deleted. The paragraph should read as follows:

After BLASTN search our sequences showed high similarity with several reliable sequences available in GenBank. Using the output alignment of ITS generated by Mega 7, a rooted tree was obtained based on Minimum Evolution method (Fig. 1). Further considerations about each taxon are presented under species description.

(2) In 'Golovinomyces asterum U. Braun, Taxonomic Manual of the Erysiphales (Powdery Mildews): 304 (2012)' section, second paragraph, second sentence, '(Fig. 4)' should be changed to '(Fig. 2)'. The paragraph should read as follows:

The online version of the original article can be found at https://doi.org/ 10.1007/s13314-020-00399-4

M. Darvishnia

mdarvishnia44@yahoo.com

1 Department of Plant Protection, Faculty of Agriculture and Natural Sciences, Lorestan University, Khorram-Abad, Iran

2 Department of Plant Protection, Faculty of Agricultural Science, Guilan University, Rasht, Iran
Most Ageratum houstonianum (blueweed) grown in the garden showed powdery mildew infections. Symptoms appeared as irregular patches on both side of leaves and sometimes extended to whole leaves and other parts such as buds (Fig. 2).

(3) In "Golovinomyces ambrosiae (Schwein.) U. Braun \& R.T.A. Cook, in Cook \& Braun, Mycol. Res. 113: 628 (2009)" section, second paragraph, second sentence, '(Fig. 5)' should be changed to '(Fig. 4)'. The paragraph should read as follows:

Most Rudbeckia hirta (black-eyed Susan) grown in the garden showed powdery mildew infections. Symptoms appeared as white mycelium which extended to whole leaves and other parts such as stems (Fig. 4).

(4) Figs. 2, 3, 4 and 5 should be re-arranged as follows: 


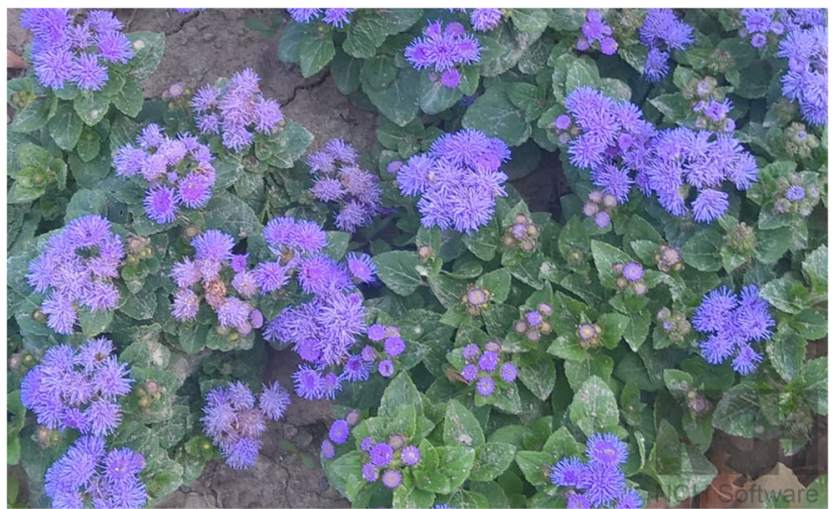

Fig. 2 Powdery mildew infection on Ageratum houstonianum (blueweed)

Fig. 3 Golovinomyces asterum a Conidiophores, b Conidia, c Drawing conidia germination \& conidiophore, d Conidia germination, e Appresorium; Scale bar $=10 \mu \mathrm{m}$
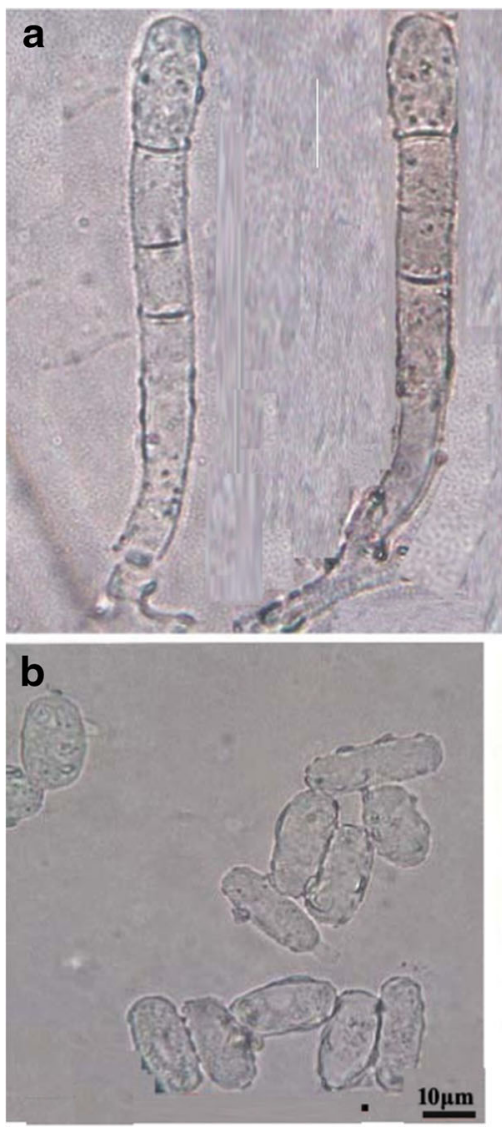
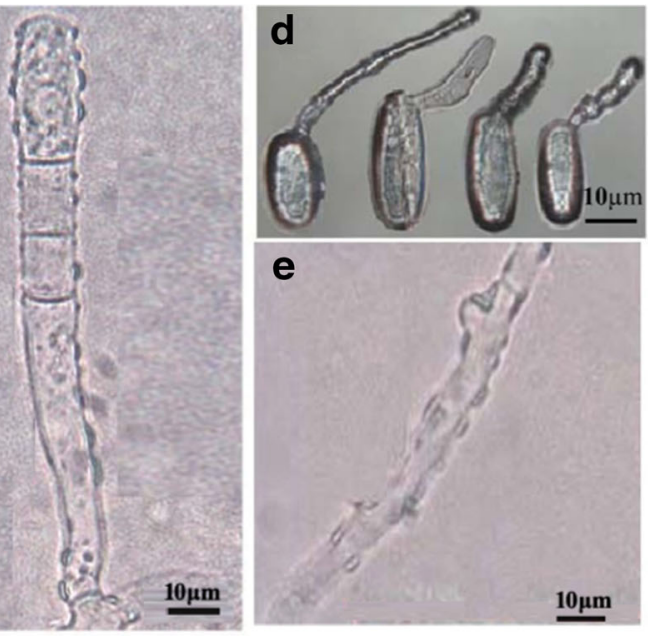

C

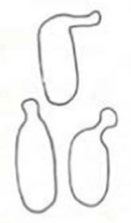




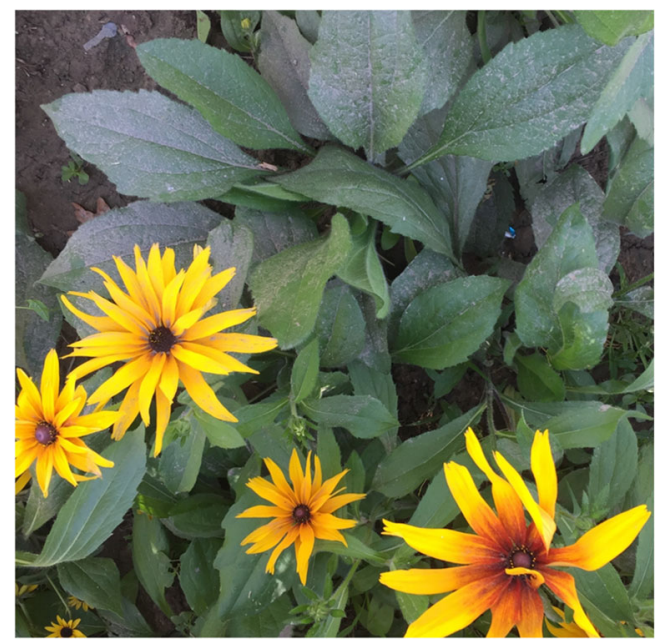

Fig. 4 Powdery mildew infection on Rudbeckia hirta (black-eyed Susan)
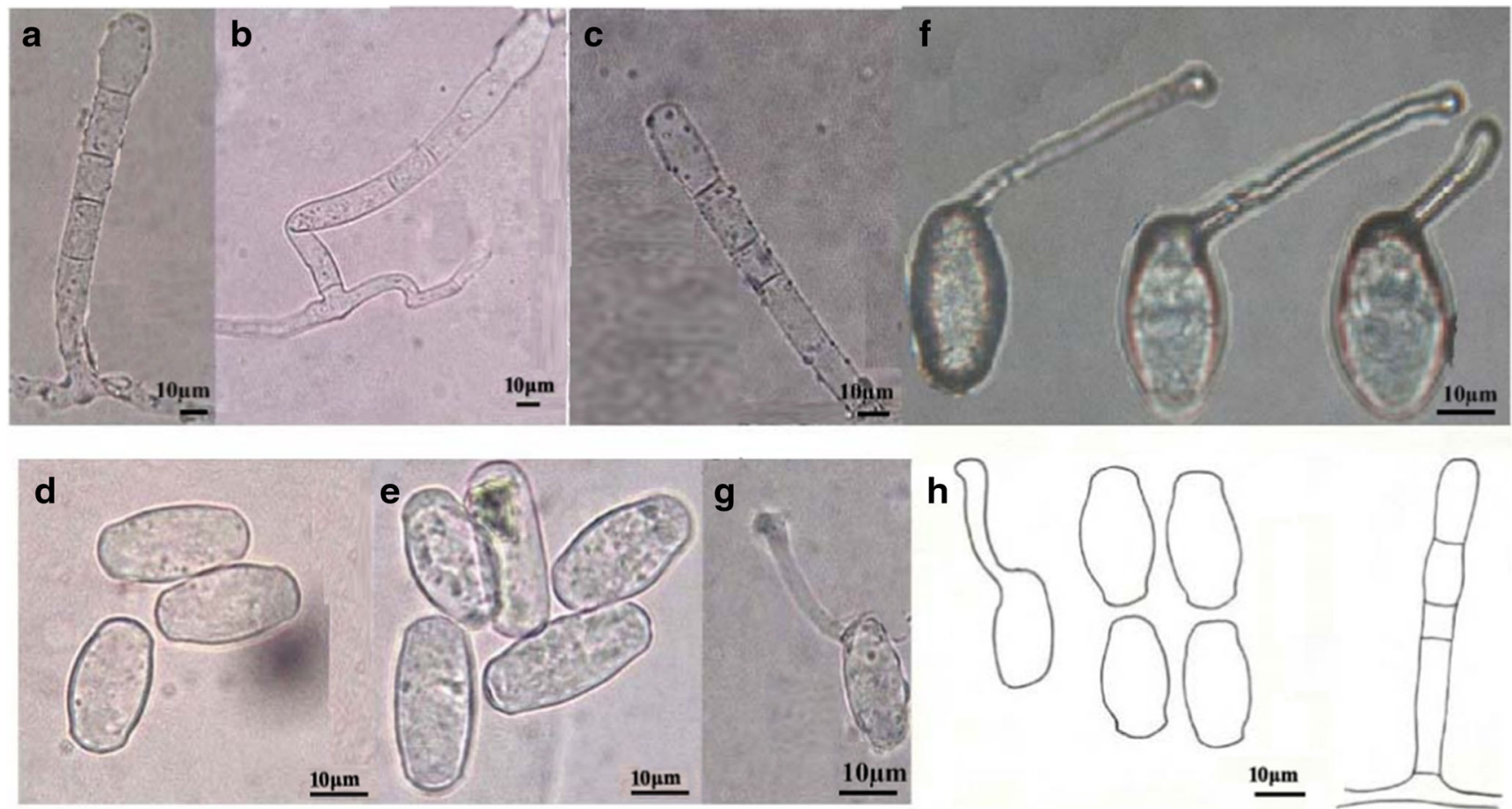

Fig. 5 Golovinomyces ambrosiae a, b, c: Conidiophores, d, e Conidia, f, g Conidia germination, h Drawing conidia, conidium germination \& conidiophore; Scale bar $=10 \mu \mathrm{m}$

The original article has been corrected. 